\title{
Identity, Belonging and Strategic Citizenship. Considerations About Naturalisation Among Italians and Spaniards Living in the EU
}

\author{
Iraklis Dimitriadis ${ }^{1}$ (D) Fabio Quassoli ${ }^{\mathbb{D}}$
}

Accepted: 27 June 2021 / Published online: 27 July 2021

(C) The Author(s) 2021

\begin{abstract}
The subject of naturalisation among intra-EU migrants has only recently drawn the attention of social science scholars. Empirical evidence from quantitative studies shows an increase in citizenship applications among this new wave of mobile people, indicating a strategic use of naturalisation. However, there is not a great deal of micro-level research, especially as to the subjective meanings attached to citizenship take-up in a new EU member state. Drawing on 68 in-depth interviews conducted with Italians and Spaniards living in London and Berlin, we argue that an individual's understanding of naturalisation within the EU context is based on two aspects: on one hand, a strictly pragmatic evaluation of the pros and cons of the new status; on the other, a new sense of belonging as well as new cultural and territorial identifications that intra-EU migrants are not often willing to experience. Therefore, this article suggests that EU migrants that strongly identify with their country of origin and the EU see national and EU identities as conflicting with naturalisation, thus setting aside instrumental considerations. This constitutes a critique to theoretical approaches claiming the diminishing importance of a nation's cultural self-understanding. Our paper also sheds light on the possible effect of the UK's departure from the EU on young Southern European migrants choosing to apply for British citizenship, highlighting that it is mostly the implementation of the formal exit process and the actual abrogation of EU citizenship rights that reconfigure patterns in naturalisation, rather than the uncertainty and fears about the future.
\end{abstract}

Keywords Naturalisation · Citizenship · Intra-EU migration · Brexit

Iraklis Dimitriadis

iraklis.dimitriadis@unimi.it

1 Department of Social and Political Sciences, University of Milan, Via Conservatorio 7, 20122 Milan, Italy

2 Department of Sociology and Social Research, University of Milano-Bicocca, Milan, Italy 


\section{Introduction}

In recent decades, the subject of acquiring formal citizenship status has attracted increasing attention in migration studies. Scholars have focused on the reasons why migrants ${ }^{1}$ apply for naturalisation within the host country, arguing that different factors may inform their decision, such as cost/benefit evaluations, their understanding of the naturalisation process, a migrant's personal characteristics, as well as institutional and contextual aspects (Aptekar, 2016; Harpaz \& Mateos, 2019; Yang, 1994).

European naturalisation studies have traditionally focused on non-EU migrants (Birkvad, 2019; Leuchter, 2014; Yanasmayan, 2015) and, more recently, a specific category of migrants known as the "onward migrants" who have used EU citizenship to relocate within the EU (see for example della Puppa \& King, 2019). However, scholars have paid little attention to intra-EU migrant attitude towards new EU citizenship and the subjective meanings ascribed to citizenship take-up (for some exceptions, see Koikkalainen, 2019; Rother \& Nebe, 2009).

Intra-EU migrants generally enjoy the same legal status and freedom of movement as nationals, as well as a series of economic and social rights, such as nondiscrimination protection within the labour market, unemployment benefits, various forms of social assistance, simpler permanent residency procedures and full political rights at local elections (Shaw, 2020). Enjoying equal treatment with nationals, EU citizens are considered less prone to naturalise within an EU country than people coming from outside the EU, and especially from developing countries (Koopmans et al., 2005). This is possibly the reason why little attention has been paid to the issue in academic — as well as political_-debates.

However, over recent years, naturalisations among EU citizens within another EU country have attracted attention, as the number of naturalisations increased from 98,422 in 2013 to 153,343 in 2018 (Eurostat). In this respect, recent academic works shed light on this trend by explaining changing patterns in citizenship takeup among intra-EU migrants (Alarian, 2017; Graeber, 2016). While Graeber (2016) states that intra-EU migrants from countries hardest-hit by the crisis (Greece, Italy, Ireland, Portugal, Spain) are incentivised to naturalise to cope with the anxieties surrounding their legal status (should the EU collapse), Alarian (2017, p.2164) claims that the Euro crisis had little impact on encouraging intra-EU migrants to apply for naturalisation. On the contrary, she claims that "rather than economic uncertainty... fears over closing borders and new citizenship restrictions may act as a catalyst propelling intra-EU citizenship applications" (e.g. Brexit). However, studies based on quantitative data and surveys provide a limited understanding of what naturalisation means to migrants compared to that gained from in-depth interviews (Bloemraad \& Sheares, 2017). Even though it would seem that contextual determinants are linked to increasing naturalisation trends (Graeber, 2016), more light should be shed on the subjective meanings associated with the decision to acquire (or not) a new EU citizenship. This is because "human agency is broader

\footnotetext{
1 According to the UN, long-term international migrant is "a person who moves to a country other than that of his or her usual residence for a period of at least a year".
} 
than cost/benefit instrumentalism ${ }^{2}$ " and citizenship acquisition may depend on feelings of belonging to an imagined community, or it may entail identity changes (Bloemraad \& Sheares, 2017, p.835).

Starting from these factors, we aim to answer two research questions: How do intra-EU migrants evaluate the possibility of applying for a new EU citizenship? What are the meanings they attribute to naturalisation and citizenship? In other words, we explore the attitudes and behaviours of Italian and Spanish migrants living in London and Berlin as regards naturalisation, in particular what German or British citizenship take-up means to them. In addition, the duality between home and host country citizenship should be seen in a broader framework, taking into account the role played by EU citizenship. Furthermore, we address the balance/importance of, on the one hand, a new feeling of belonging - as well as the desire to fully participate in the social/ political life of their new political community - and, on the other, a rational evaluation of the balance between advantages and costs. Lastly, we provide some insights into the impact of Brexit on driving EU migrants to consider applying for naturalisation.

\section{Citizenship Concepts and Reasons for Applying for Citizenship}

The notion of citizenship has been traditionally linked to a set of rights and obligations within the nation-state, "the sole source of authority of citizenship and democracy" (Isin \& Turner, 2002 p.4). Being a citizen within a specific state is also deemed to imply attachment to-and identification with - the nation, as well as a desire to take part in its political life.

However, over recent decades, the concept of citizenship has been challenged by a series of emerging social issues. On one hand, the ideas of "post-national" citizenship (Soysal, 1994) and "inevitable lightening of citizenship" (Joppke, 2010) have come to light, marking the declining relevance of national citizenship. In this regard, multiple overlapping legal frameworks make this set of rights that, both at an individual and collective level, provide a broader definition of citizenship, more flexible, contingent and difficult to enforce. Similarly, the emergence of transnational communities and right to dual citizenship have further blurred the boundaries of belonging and citizenship, as transnational migrants may identify with - and politically take part in-both home and host societies (Bauböck, 2010). Moreover, increasingly diverse contemporary societies challenge the strictly legal perspective of citizenship as full membership of a nation state (Koopmans et al., 2005). Political and social struggles to gain recognition of the status of migrants also led social scientists to see citizenship "as a social process used by individuals and social groups to claim, expand or lose rights" (Isin \& Turner, 2002, p.4). Isin goes even further in his book, Theorizing acts of citizenship (2008), by stressing that analyses should focus on how subjects use "acts of citizenship" to constitute themselves as citizens.

\footnotetext{
2 According to Harpaz and Mateos (2019: 844) instrumentalism or strategic use of nationality refers to: "three domains: (a) acquisition strategies (for example, citizenship reacquisition on the basis of ancestry or ethnicity); (b) instrumental uses (for example, citizenship as insurance policy or as a premium passport) and (c) perceptions (for example, citizenship as a commodity, status symbol or an ethnic marker)".
} 
In the same way-and regardless of the principles driving each country to recognise citizenship (ius sanguinis, ius soli or ius domicili, Koikkalainen, 2019)_ Monforte et al. (2018) have pointed out that a crucial change is underway in EU countries: we are moving away from the idea that citizenship is just a crucial step in the integration process, to that of something "deserved" and "earned", a reward to be accorded those migrants who prove themselves on both a linguistic and cultural level, mastering the language and demonstrating knowledge of the history, values and laws of the host country.

Returning to the main point of this research, literature on the reasons for applying for citizenship has focused both on individual and structural factors.

As for the former, those migrating at a younger age receive higher incomes, have better language skills, more education, are residents for longer and have no intention of returning and therefore most likely to apply for citizenship. As for the latter, the likelihood of naturalisation increases when migrants are from less democratic or poorer countries, arriving in host countries where there are fewer ethnic groups and citizenship policies are more accessible (Yang, 1994). It also seems that pro-migrant host societies favour naturalisation, whereas exclusionary environments may either incentivise naturalisation (as a defence mechanism against either social or political exclusion) or discourage migrants from applying for citizenship (as a reactionary practice).

As far as the latter is concerned, subjective decisions about citizenship acquisition can be linked to three different dimensions.

First, citizenship may be either a strategic device, enabling migrants to both strengthen their legal status within the host country (Dimitriadis, 2018; Finotelli et al., 2018) and obtain rights to move and work in countries offering better economic opportunities and access to welfare benefits (Della Puppa \& King, 2019). This dimension may also be a defence mechanism in times of crisis, as shown by two recent unsettling events in Europe. On one hand, the acquisition of EU citizenship enables non-EU migrants to escape economic recessions in Southern Europe (Ambrosini, 2018) and move to other EU countries (Graeber, 2016). On the other hand, both non-EU and EU migrants may apply for British citizenship to secure their status within the UK following the Brexit referendum results (Alarian, 2017; Guma and Dafydd, 2019).

Second, citizenship may be considered a symbol of cultural belonging and means of committing to new cultural values (Joppke, 2010) with significant repercussions in terms of self-redefinition. Bloemraad and Sheares (2017) found that naturalisation may be linked to migrants "feeling at home" in the host country and a way of identifying with the nationals. In this respect, length of residency in the new country seems crucial and migrants may see naturalisation as part of their full integration once they have lived there for many years (Aptekar, 2016).

Third, citizenship may have a political/ideological value and indicate political belonging within the host country (Bloemraad \& Sheares, 2017). It could be considered a precondition for full political participation both at a local and national level. In this context and in the event of weak material incentives for intra-EU migrants, applications for dual citizenship would indicate repositioning towards their own political community of reference. Therefore, this new citizenship could have a predominantly political value, further underlined in countries still largely dominated by 
national demons, ${ }^{3}$ by the weak grip of European citizenship: a "citizenship without identity" that frees individuals from the "suffocating grip of nation-states", and that is "solely about rights with no complementary duties whatsoever, decoupled from even the thinnest of identities" (Joppke, 2019, p.870).

\section{British and German Regulatory Frameworks on Citizenship Acquisition and Dual Citizenship by Italian and Spanish Migrants}

Before discussing the main results, let us bear in mind that the regulatory frameworks governing access to citizenship rights are considered to be of relevance to naturalisation rates, as institutional contexts of origin and destination, namely institutional and policy environments (Vink et al., 2013). We will then present data on the Italian and Spanish migrant populations in the UK and Germany, as well as recent trends in Italians and Spaniards applying for citizenship in the UK. ${ }^{4}$

EU citizens can apply for German citizenship once they have resided in the country for 8 years, demonstrated civic integration (demanding an oath of loyalty to the German constitution and a good knowledge of the German language and culture), are economically independent and have a clean criminal record. According to Koopmans et al. (2005) long and time-consuming administrative procedures to apply for German citizenship and proof of language and civic integration implemented in the 2000s have resulted in low naturalisation rates (Vink et al., 2013).

In the case of Britain, applicants have to demonstrate sufficient knowledge of both the language and life in the UK (either by passing the Life in the United Kingdom test or attending combined English language and citizenship classes), obtain permanent residency status after living in the UK for at least 5 years and be of "good character" (certified by the Police). In addition, UK citizenship policies require that migrants, wishing to naturalise, identify with "British values in order to facilitate their integration". One aspect the UK and Germany have in common is the idea, spread throughout the European Union in recent years, that citizenship is a reward for successful integration. An idea that, according to some critical scholars, can result in alienating and marginalising new citizens (Bassel et al., 2018).

Both Italians and Spaniards can apply for dual citizenship in the two selected countries without having to give up their Italian or Spanish nationality respectively. While in the first case Italian citizenship is automatically retained, Spanish citizens who acquire a foreign citizenship and habitually reside abroad $^{5}$ have to declare their desire to retain the Spanish one (de Groot et al., 2011).

Online statistical sources relating to the acquisition of British and German citizenship among Italian and Spanish migrants in the two countries (data.gov. uk and destatis.de), would seem suggest that the increase in the total number of

\footnotetext{
3 By using metaphorically the expression "national demons" we refer to the inextricable link between citizenship as a set of rights and citizenship as political and cultural belonging.

${ }^{4}$ Data on citizenship applications in Germany was not available.

5 Except for those residing in Latin American countries, Andorra, the Philippines, Equatorial Guinea and Portugal.
} 


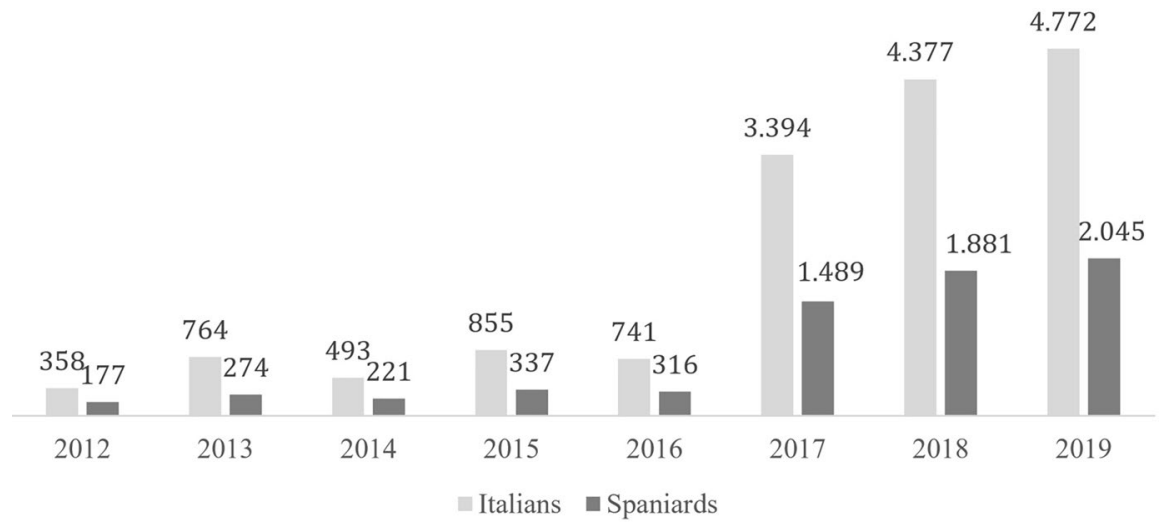

Fig. 1 Total number of Italians and Spaniards applying for naturalisation in the UK from 2012 to 2019

naturalisations over the last few years reflects the increasing number of Italians and Spaniards within the two countries since 2009 (Lafleur \& Stanek, 2017; Author $\mathrm{XXX).} \mathrm{However,} \mathrm{looking} \mathrm{at} \mathrm{the} \mathrm{total} \mathrm{number} \mathrm{of} \mathrm{Italians} \mathrm{and} \mathrm{Spaniards} \mathrm{applying} \mathrm{for}$ naturalisation in the UK, in more detail, shows that this number has soared since 2017 (Fig. 1). From 2016 to 2017, the Home Office received almost 4.5 times more applications from Italians (from 741 to 3394) and 4.7 from Spaniards (from 316 to 1489). This trend rose even more in the following 2 years. On the basis of our interviews, we will try to account for such a drastic change in the attitude of Italians and Spaniards towards acquiring British citizenship in the following paragraphs.

\section{Methods}

Our empirical results are based on 68 in-depth interviews with Italians and Spaniards (34 men and 34 women) living in London and Berlin, considered two global, multicultural and cosmopolitan cities, thus luring migrants from all over the world (Griffiths \& Maile, 2014; King et al., 2018). Table 1 provides the demographic characteristics of our participants. Over half of participants are between 18 and 35 years old, most of whom migrated individually during the 2010s. More than twothirds of them (48 out of 68) were employed in high and medium-skilled sectors, whereas 21 are lower skilled workers and/or having lower skilled jobs. ${ }^{6}$ The sample

\footnotetext{
${ }^{6}$ Only one out of 68 participants naturalised abroad, so the article reflects prospective decisions for citizenship. Interviewers asked the same questions to all participants in relation to their intention to apply or not for naturalisation: "Are you planning to apply for the British/German citizenship"; "What does this mean for you". Some of the empirical material analysed below comes from participants' answers to questions related to their self-identification and sense of belonging: "Do you still feel Italian/Spaniard", "Do you now feel (more) European/British/German"? These questions were included in an interview outline of a research project focusing on lived experiences of intra-EU migrants. The interview outline contained nine sections: (a) participant presentation and background; (b) previous experiences of migration; (c) the decision to migrate; (d) preparation before the departure; (e) the arrival; (f) the life abroad; (g) identity, belonging and citizenship; (h) neighbourhood and social life; (i) future plans.
} 
Table 1 Our sample

\begin{tabular}{lllll}
\hline & & Italy $(N=41)$ & Spain $(N=27)$ & Total $(N=68)$ \\
\hline Gender & Men & 19 & 15 & 34 \\
Age & Women & 22 & 12 & 34 \\
\multirow{4}{*}{ Destination country } & $18-35$ & 30 & 17 & 47 \\
& Over 35 & 11 & 10 & 21 \\
Time since migration & UK & 20 & 14 & 34 \\
& Germany & 21 & 13 & 34 \\
Marital status and family & Less than 10 years & 39 & 26 & 65 \\
& More than 10 years & 2 & 1 & 3 \\
& Single/separated & 27 & 13 & 40 \\
Educational level according & Married/de facto couples & 14 & 14 & 28 \\
to International Standard & Of whom with children & 11 & 7 & 18 \\
Classification of Education & 2 & 1 & 3 & 4 \\
(ISCED) & 3 & 4 & 2 & 6 \\
& 4 & 2 & 1 & 3 \\
& 5 & 1 & 1 & 2 \\
& 6 & 7 & 10 & 17 \\
& 7 & 25 & 10 & 35 \\
Sector & 8 & 1 & 0 & 1 \\
& High-skilled & 29 & 19 & 48 \\
& Low-skilled & 12 & 8 & 20 \\
\hline
\end{tabular}

of participants is based on (a) the preferred destinations of new intra-EU Italian migrants (UK and Germany); (b) some socio-biographical characteristics (age, gender, education); (c) the employment sector, distinguishing between high-skilled and low-skilled jobs (Coletto \& Fullin, 2019). It also takes into account any "deskilling" phenomena university educated and lower skilled workers may be subject to during the migratory process.

Participants were recruited through a variety of means, including snowball techniques, publishing calls for participation on Facebook pages dedicated to the Italian and Spanish communities abroad, as well as through professional and political organisations, online and LinkedIn searches and personal contacts. These techniques were particularly useful in that we were able to recruit participants with different demographic characteristics and employed in different economic sectors. After establishing numerous initial contacts, we were able to select all the participants who saturated our typology. Interviews were conducted face-to-face in Italian and Spanish $^{7}$ from November to December 2016 (London) and from November 2016 to February 2017 (Berlin), and lasted between $40 \mathrm{~min}$ and $2 \mathrm{~h}$. Data was tape-recorded

\footnotetext{
7 The two interviewers were PhD students in Social Sciences with a solid methodological competence in qualitative methods for social research. The linguistic competences of both researchers (in Italian and Spanish languages respectively) were close to those of a native speaker, and both of them had been living in Italy and Spain for about 5 years before the research.
} 
and is stored at the UK data archive, whereas transcripts of each interview are in their original language (Italian and Spanish). Quotations used in the findings were translated into English. The majority of interviews were conducted in cafés or private homes. Considering ethical issues, we developed an informed consent form for participants to sign before they took part in the research. It included information on the nature of the research, risks and potential benefits, responsibilities and confidentiality, as well as the voluntary nature of participation. Interview transcripts were coded using MAXQDA data analysis software. Then, according to grounded theory methodology, we started our analysis with substantive coding (both open and selective) and proceeded with theoretical coding until we achieved theoretical saturation through constant comparison (Glaser, 2005). In other words, the coding process was initially data-driven and then involved thematic coding to ascertain the extent to which the nodes reflected what said by participants. Thirteen themes and 155 subthemes emerged in the (name of the project) research project, but the analysis in this article draws on themes and sub-themes that relate only to considerations on naturalisation and citizenship, sense of belonging and identity. Tables were also produced for each of the 68 participants to explore how and if gender, education, employment, family, future plans and durations of stay interplay with their considerations on citizenship and naturalisation.

\section{Findings}

\section{Balancing Costs and Benefits}

Italians and Spaniards residing in the UK and Germany tend to calculate costs and benefits carefully before deciding whether to apply for a new citizenship or not. Only a few of our participants mentioned the amount of fees, bureaucracy, language tests and proof of civic and social integration involved in the UK and Germany when referring to their desire to naturalise or not. Even though a couple of participants identified bureaucracy and financial costs as deterring factors in getting British citizenship, no other types of costs were mentioned. Conversely, considerations around costs were offset by greater benefits such as access to rights and secure economic opportunities and international mobility (Bloemraad \& Sheares, 2017). Similarly, apart from some confusion among participants as regards the degree of compatibility between their original nationality and second EU one (e.g. German or British), the ability of Italians to have dual citizenship and the possibility for Spaniards to maintain their first citizenship are not preventing our participants to apply for naturalisation.

Recent studies suggest that the UK was an attractive destination for EU citizens wishing to move for study and work reasons; however, this trend fell sharply after the result of the EU Referendum on June 2016 (The Migration Observatory).

All in all, decisions to apply for British citizenship were mostly driven by a sense of insecurity as to their legal status and were overwhelmingly linked to the Brexit event. Consequently, it may be based on more serious and calculated evaluations on the part of some migrants, especially for those with families who plan to settle in 
the UK in the long term. These mirror anxieties around loss of EU citizen rights to free movement and residence in the UK after Brexit, bringing to mind the notion of "defensive naturalisation" (Aptekar, 2016).

An Italian participant married to a conational and with one child, who has also bought a flat and intends to remain in London permanently, is going to apply for citizenship. He declares that "when Article 50 expires [...] they [British government] could easily decide that all migrants have to go back home" (Italian, UK, M, aged 35). Applying for naturalisation can thus be a strategic decision to allay fears of insecurity (Alarian, 2017).

While our analysis showed no relevance between gender and such kind of strategic considerations, we looked at differences between people employed in high and low-skilled economic sectors. A Spanish cinema attendant and an Italian engineer, both in London, recount:

Basically...to make things easier. Not because I feel British or Spanish, or whatever. I know that if I apply for British citizenship over the next three years, because it's been a few years [that I've been in the UK], with Brexit and everything, it'd be much easier for me to stay in this country if I wanted to. Finding a stable job where I won't get into trouble for being a foreigner. (Spaniard, UK, F, aged 25)

We'll see, now we're waiting for the decision of the Supreme Court in December and we'll see if they'll really leave Europe. I don't feel in "danger" from a professional point of view. Just as I came here, I can move somewhere else if I have to, or I could return to Italy-I'm not worried. (Italian, UK, F, aged 27)

These quotations suggest that Brexit and the current climate in Britain have meant that utility-maximising logic based naturalisation incentives have increased not only among those with families aspiring to settle in the UK long term, but also among low-skilled and poorly educated migrants. Unlike their university-educated peers who might benefit from earlier socialisation in a "culture" of European mobility through the Erasmus programme and for whom the costs of 're-migrating' may be relatively low (Favell, 2008), lower skilled individuals may believe the economic and cultural costs of a second round of migration from the UK to a new destination to be too high. In addition, this attitude might reflect the fact that anti-immigration debates mainly regarded low-skilled and low-educated migrants. On one hand, limited concerns among high-skilled migrants as to their professional future in the postBrexit period may be also attributed to the fact that many of them have been treated in a discretionary way. Some have received personal invitations from the Home Office to apply for pilot schemes granting citizenship to pre-settled and settled EU citizens, whereas in other cases, employers have covered the fees for such a procedure. ${ }^{8}$ On the other hand, there were widespread concerns among low-skilled workers on the possible constraints within the labour market, in particular among Spanish participants. It could be that Italian low-skilled workers feel more protected in the London labour market due to the significant number of Italian entrepreneurs (Italian

\footnotetext{
${ }^{8}$ See for instance: http://www.ox.ac.uk/news-and-events/oxford-and-brexit/settlement-fees.
} 
bar and restaurant owners etc.). They may even consider returning home as an alternative option, since low-skilled jobs (although precarious or low-paid) are always available, even during the crisis (Dimitriadis et al., 2019).

It could be also added that anxieties around EU citizens' legal status due to other unsettling events (for instance, the Eurozone crisis in Graeber, 2016) were rare among participants. Only an Italian woman in Berlin makes such an instrumental consideration around German citizenship.

Acquiring citizenship may also lead to symbolic recognition or access to opportunities (Birkvad, 2019). A Spaniard planning to apply for citizenship states:

I see everything that has to do with nationalities in instrumental terms. [...] I'd apply for German nationality if I were planning to live here [for a long time] as it would make a lot of things easier at an administrative level. (Spaniard, Germany, M, aged 29).

The quotation suggests that citizenship is considered to bring normative legitimacy resulting in equal rights among (German or British) community members, namely the desire to be better served by public and administrative services. This same idea was cited by other participants, even though this may appear inconsistent when considering the principle that EU migrants should be treated in the same way as nationals in other member states. This was especially true in the case of Germany ${ }^{9}$ where citizenship take-up rates have been traditionally low (Vink et al., 2013).

Similarly, a dark skin Italian participant living with his family in Berlin, who had no intention of returning home, claims:

$100 \%$ yes! Yes, it's normal, because then you have more rights, right? [...]

You don't have to present your Italian identity card to the police, you have less problems, you have less controls, because here the police check you from head to toe when you're Italian ... [when you go] in hotels, restaurants, public offices, insurance services: you have more advantages with a German identity card. (Italian, Germany, M, aged 28)

In this case, citizenship can make migrants feel more protected against the risk of racial profiling and can be seen as a guarantee against possible discriminations. Despite only few migrants reported discrimination by public authorities, previous works have shown that formal membership makes relationships with the state institutions "easier", since intra-EU migrants in precarious forms of employment could even face the risk of expulsion from a member state due to erroneous interpretation of EU legislation (Simola, 2018).

Last but not least, some participants consider becoming British or German citizens as a symbolic marker of equality and belonging (Birkvad, 2019). This is, for instance, the case of an Italian IT entrepreneur living in London who experienced some discrimination because of his English accent during business meetings. He

\footnotetext{
9 Administrative measures may hinder EU migrant integration in Germany when considering, for example, that all foreigners must be registered as residents (Anmeldung), only possible with a job contract. Therefore, it is impossible for migrants to be formally registered as a resident if they do not have a job before arrival.
} 
states that he would be in a better position with a British passport, confirming how acts of social (mis)recognition may shape desires for naturalisation. In his words: "I would be better represented with a British passport rather than an Italian one". (Italian, UK, M, aged 40).

Even though in many cases naturalisation is a means to an end, the majority express different rationales and emotions as regards citizenship that go beyond or co-exist with cost-benefit evaluations as shown in the following section.

\section{The Uncertain Meaning of Citizenship as a Symbol of Cultural Belonging}

A prime example of a new citizenship going beyond pure instrumentalism is those individuals who are either reluctant to be identified culturally as typical Brits or Germans or associated to German or British civic/national culture. A young Italian participant who does not wish to apply for naturalisation says: "I feel very different to the Germans [German cultural traits], too different. And I don't even want to get too close". (Italian, Germany, M, aged 29).

With this statement, this participant expresses a certain amount of unease to the idea of acquiring German citizenship and clearly links naturalisation to his feelings about German culture. In fact, some participants felt that dual citizenship would make them definitely German or British and were unhappy with such a change in their cultural identity and traits. They point out a marked cultural difference between the host society and country of origin and stress the symbolic relevance of citizenship in terms of national belonging (Leuchter, 2014). Such an attitude was common among our participants and indicates that the issue of citizenship is considered to be one of national belonging. In the following lines too, Italians and Spaniards feel that acquiring a new citizenship could involve a redefinition of their sense of belonging and identity, which is in contrast with Soysal's (1994) groundbreaking work describing the link between territory, identity and rights as a post-national concept of citizenship.

Another participant, when asked about his intentions to apply for German citizenship, declares that: "I don't think so [apply for German citizenship]. I'd like to return to Italy, but actually I don't feel German. I've remained very attached to Italy". (Italian, Germany, M, aged 29).

This statement suggests that sense of no affinity to German culture, commitment to the Italian national community and firm entrenchment in the national identity imply that naturalisation is all but desirable. Contrary to other studies suggesting that non-EU migrants downplay the effects of a new citizenship on their identity to cope with the fact they cannot hold dual citizenship (Yanasmayan, 2015), our participants place a high symbolic and emotional value on their home country nationality-which they often equate with identity. Overall, citizenship remains intrinsically linked to national identity even when there are no barriers to free-movement. Thus, they tend to view another citizenship, and therefore, another identity, as (symbolically) incompatible with their self-understanding. ${ }^{10}$

$\overline{10}$ As was previously the case, no substantial differences emerge between men and women. 
Furthermore, and contrary to the assumption that the likelihood of naturalisation increases with education, this approach does not seem to be influenced either by the level of education or sector in which they are employed. For instance, an Italian working in the financial sector declares: "I won't ever do it! Would you like to explain to me why not? Because I'm Italian, I'm not German!”. (Italian, Germany, F, aged 28).

Another issue that is of great interest in our research is how attachment, referred to a sense of belonging to the EU community, may shape decisions on whether or not to apply for naturalisation. An Italian living in Germany claims:

I continue to feel Italian. I believe a lot in Europe. So, I feel Italian in the sense of where I come from ... The question 'where are you from?' ...It's a part of the baggage. However, believing a lot in Europe, I see it very much as a possibility for enrichment. (Italian, Germany, M, aged 31)

The above quotation indicates that attachment to the European community, rather than being separate, is usually intertwined with both feelings of attachment to the country of origin and, at times, a refusal to belong to the host society. This is in line with Rother and Nebe's findings (2009) as regards Italians and Spaniards' feelings of belonging across Europe. On one hand, they argued that Spaniards and Italians are very attached to the EU, but equally identify with Spain and Italy. However, on the other, feelings of attachment to the host country are quite low. This "feeling Italian/Spanish" shows their cultural and territorial roots, while Europeanness overlaps national identity and accounts for a global or cosmopolitan citizenship (Strumia, 2017). In this sense, EU citizenship could be a layer of multi-level citizenship, which does not necessarily surmount member states.

In the same way, two Spaniards, a telecommunications engineer who moved, with her husband and two young daughters, to a small city outside London and a physician living in Berlin who is married to a German man and has two German-born young sons state, respectively:

Of course I feel more European [now]. I feel more 'a citizen of the world', you feel...you still feel Spanish [...] I feel more international, in general. Not exactly more European, but more international. In addition, we live in a globalized world where it doesn't matter where you end up working and living. (Spaniard, UK, F, aged 38)

I've been asked this a lot, why I haven't taken up German nationality. But why would I? I'm in the European Union and therefore don't feel German. Being Spanish, you have no problems in moving around or travelling, so I maintain... [my single nationality]. And what I'd like is for my sons not to lose the language [Spanish], nor their roots [in Spain]. I try to talk a lot about Spain, to make sure they're in touch with my mother and with my siblings. When Spanish friends come to visit, I want them [sons] to feel a little bit Spanish. (Spaniard, Germany, F, aged 39)

The account of the first participant reiterates how attachment to both EU and national identity coexist. While continuing to feel Spanish, she sees Europeanness 
to be linked to a cosmopolitan/global identity. The second quotation indicates that identification with his/her own country of origin and a strong feeling of being part of an imagined category of Europeans may prevent intra-EU migrants both from applying for dual citizenship and developing any affinity for the host country population and culture. Despite displaying a high level of local integration, she rejects the idea of adopting German citizenship on several grounds. Firstly, like numerous participants in our international case studies, because she does not consider the benefits to be that enticing compared to EU citizenship. Secondly, because she equates the new citizenship with a sense of cultural loss.

Similarly, an Italian living in Germany tells us:

I'm not interested in [applying for naturalization], because I hope Europe will remain united as it is, so that I can go anywhere with a European passport. I don't feel German. I don't even want to feel German. (Italian, Germany, F, aged 28)

Perceiving the combination of European and territorial identities as conflictual, this participant refuses to identify with German culture, while his attachment to Europe is translated into the possibility of free mobility. This differs from a non-EU migrant view of EU citizenship in its social sense (Birkvad, 2019), as Italians and Spaniards enjoy the benefits of EU citizenship. Another of our participants, a Spanish male analytics manager living in Berlin, adds that:

[As a result of an Erasmus exchange and Masters programme in] Maastricht and Denmark...I've ended up feeling more European. [...] I didn't have many expectations when I came to Berlin. The only minimum expectation that I had was in terms of the job experience and the experience of living abroad. But I've found much more than that. I've found friends, I've found...I don't know, values that I didn't have before, I've developed a much broader view of the world. (Spaniard, Germany, M, aged 29).

In this case, identification with Europe and feeling of belonging to a global community-i.e. cosmopolitanism-can be traced back to previous intra-EU mobility experiences-through, student exchange programmes such as ERASMUS - and is more common among highly educated participants. Consistently to both Favell (2008) and Ranta and Nancheva (2019) conclusions, also in our results intra-EU migration is linked to a transnational European identity, in that mobile Europeans tend to foster a collective identity and sense of belonging, which are seen as requirements for European integration.

Moving now to how Brexit impacts considerations around naturalisation, let us consider the following excerpt of an interview with an Italian architect living in London:

Brexit really horrified me, to the point that I said, "I'll stay in this [architect's] firm for a while, at least until I finish my current project." Let's see how things unravel, but it has certainly made me lose a lot of respect for this country and encouraged me to [look] elsewhere. (Italian, UK, M, aged 29) 
As this example shows, it is not unusual for participants who dwelled on the exclusionary nature of the Brexit experience to begin shaping personal and career plans outside Britain and explicitly rejecting the notion of securing their residency, for example, through naturalisation, even though such considerations underestimate the difficulties another migration might involve due to the lack of language skills in a hypothetical new destination. Other participants also talk about moving to another EU country. A Spaniard living in London claims:

If they don't want me here, then I don't... [getting British citizenship] costs 1,000 Pounds... and I don't need it. If they don't want me [now], they won't want me with or without [British] citizenship, so I'll leave. I don't want to be where I'm not wanted. (Spaniard, UK, M, aged 34)

This quote reveals the Brexit effects on belonging and citizenship attitudes, in the sense that the results of the referendum triggered feelings of exclusion and undesirability. Such a reaction can be accompanied with a growing disregard for the country of residence and its people, which can deter EU migrants from naturalisation. In particular, it can be argued that the Brexit referendum and resulting outcome strengthened individuals' sense of European identity and commitment to the European project. It also sparked feelings of betrayal and rejection, especially given the centrality of the migration debate during the Brexit electoral campaign. Therefore, previous student mobility experiences may not be the only factor contributing to EU identity - thus less incentive to naturalise with another EU member state-but also unexpected contextual events (Rother \& Nebe, 2009) impacting on assessments based on symbols and values.

Besides, reinforced migrant identity and forming negative views of host society culture are reminiscent of what is known as reactive ethnicity in migration studies (Portes \& Rumbaut, 2001). This means that migrants tend to strengthen their ethnic identities when they do not feel welcome in their host countries and experience discrimination or social exclusion. Similarly, the ethnic resilience perspective (Portes $\&$ Bach, 1985) suggests that the more aware migrants become of both the position of their national group within the host society and discrimination they experience, the more they resist assimilation and refuse to identify with the natives and, consequently, naturalise. This idea applies, in particular, to migrants with higher levels of education and those more aware of the political situation within their host societies (Yang, 1994). Whereas, the level of education was not of great relevance. It would seem that the Brexit crisis mainly incentivises migrants with families (and Spaniards employed in low-skilled sectors) to apply for British citizenship in order to secure their legal status.

Contrary to the above negative views on naturalisation, an Italian midwife who has lived in the UK for almost 6 years expresses a positive view on naturalisation:

I don't see it [British citizenship] either as a tragedy or a celebration. I see it as a natural thing: I've lived a big part of my adult life here, so I think it'll make things simpler and it would make me feel proud [...] but it doesn't even mean giving up my (Italian) citizenship [...] I'd like to feel a bit 'English, I bought the book to take the citizenship test many years go, but I haven't finished it yet, 
I don't know whether unconsciously I don't want to finish it or not. For sure, I feel Italian, I feel part of my community and I'd like to give back what I was given in my country. (Italian, UK, F, aged 28).

A positive predisposition towards acquiring British or German citizenship may occur when people consider new citizenship as the result of a long pathway to socioeconomic integration within the host society. In the case of this participant, naturalisation could be seen as the natural outcome of several years of settlement. She stresses the link between British citizenship and equality, a desire for social recognition (Birkvad, 2019). Yet, this does not automatically indicate a sense of belonging to the UK, even though it would be desirable. In fact, her account seems to focus on attachment to national identity and commitment to Italy ("give back what I was given"). This is also reminiscent of what Bassel et al. (2018) stated about naturalised migrants feeling they deserved citizenship, in the sense that only "good citizens" deserve it.

\section{What Kind of Political Engagement?}

Few participants may see citizenship under a political and civic engagement lens. A Spaniard living in Berlin, despite the fact that he is less incentivised to consider applying for German nationality one day because he has EU citizenship, states:

It would be interesting to be able to take part...I mean, you need to become involved, you can't keep on living in Spanish all day and then expect to take part in German life. You can take part in German life, but you need to be informed, you'd need to have a stake in the [political] problems of Germany. (Spaniard, Germany, M, aged 50).

The above participant seems to be one of the few aspiring to "full membership" of the political community in the host country. He recognises that German citizenship may be the "missing link" in allowing him to better integrate into the new political community. A second example concerns an Italian participant who has a positive view of naturalisation (highly educated engineer):

It would arouse greater interest in the context in which I live. I could vote, for example, not just for my neighbourhood ... It could trigger an interest in reading the German press, getting information through other channels [about German politics]. (Italian, Germany, M, aged 31)

Consistently with what Bloemraad and Sheares (2017) stated, the two former excerpts highlight that getting a new citizenship could also be linked to a civic dimension. It implies identification with the nation and, since it involves the acquisition of full political rights, strengthens the desire to participate in the political life of the country of immigration.

However, as far as this point is concerned, our results show that only a few participants in our study consider the possibility of naturalisation because they wish to gain full political rights in the host society. Two participants declare: 
I've been activated enough, also because, after acquiring citizenship, the main reason to obtain citizenship was to take part in the elections, mainly political, I don't have many other concrete benefits as I am a European citizen. From that point of view, as I said, participation yes, I'd like to start taking part in political life in the sense of voting, but actively, in the sense of participation, not in political parties. (Italian, Germany, M, aged 31)

I could apply for citizenship [...] But I'd have no particular advantages. The only thing would be that I could vote here, vote for all the elections. (Italian, Germany,

M, aged 30)

In the last two quotations, the political relevance of full citizenship is reduced to the act of voting. However, voting in itself can be even of little relevance, as the second Italian participant affirms. These results do not differ among participants sharing different characteristics, but confirm previous research on both EU and non-EU migrants (Birkvad, 2019; Leuchter, 2014; Yanasmayan, 2015). First, our case studies not only show that a new citizenship has little to do with political motivation, but also that Italians and Spaniards residing in the EU rarely avail of the possibility to engage in transnational political activities. Furthermore, and consistently with what Muxel (2009) suggested, our respondents' interest in politics rarely goes hand-inhand with effective political involvement, neither in the homeland nor in the host society. Second, citizenship as agency and everyday practice that can both anticipate and transcend the acquisition of rights-providing a framework for political mobilisation (Isin, 2008) — seems to have little relevance in our case, as very few of our participants associate citizenship to claiming rights and recognition. Third, the right to vote in British or German national elections is of little interest among our participants and is not perceived as such as an incentive to justify the material and immaterial costs of naturalisation (Koikkalainen, 2019; Leuchter, 2014). Even though this "denationalised freedom" (Favell, 2008) linked to cosmopolitan lifestyles in global European cities such as London, Berlin or Paris may favour local and transnational membership (Koikkalainen, 2019), it can also result in a lack of the most important civic duty, that of voting in national elections.

\section{Discussion and Concluding Remarks}

This article aimed to explore what motivates EU migrants to seek naturalisation in another EU country and what a new citizenship means to them. Overall, our findings allow us to give some answers to these questions, thus contributing to the debate on citizenship acquisition.

First, our analysis shows that meaning, attachment and sense of belonging among intra-EU migrants are of great importance when it comes to naturalisation. Even though a series of costs and benefits are taken into account, these are often of secondary importance when migrants feel attached to imagined national or European communities, or when identities are thought to conflict with belonging to the host country. Since both Italians and Spaniards can retain their original citizenship, such 
a finding reveals that they tend to consider citizenship not only in terms of a set of rights, but also a status with a highly symbolic value. Applying for a second citizenship means leaving the political community acquired at birth to develop new attachments and identities, a new political loyalty and cultural horizon. This is also a critique of those theories on citizenship that claim international migration and increased diversity within cities challenge a nation's cultural self-understanding of migrants (Koopmans et al., 2005, p.4). Overall, this culturally rooted understanding of citizenship seems to influence EU migrant attitudes to the prospect of naturalisation, thus individuals who see their nationality as an essential part of their identity are reluctant to investigate and enjoy the potential benefits of acquiring dual citizenship.

Second, such an attitude seems to be reinforced by the belief that the EU citizenship framework can - and should—provide full access to citizenship rights in all EU countries. This makes the duality between home and host countries more complex, and reduces the incentives to apply for and acquire a second EU national citizenship. EU citizenship is perceived in terms of both rights (Joppke, 2019) and belonging to a transnational/global community that do not call for reviewing their own political symbols or superseding a previous nation's cultural self-understanding with another one (Bellamy, 2008). Thus, it is perceived as a strategic resource enabling intra-EU migrants to study, work and travel without restrictions within a transnational geographical space.

Third, as far as their legal status is concerned, the privileged condition experienced by our participants compared to that of migrants from outside the EU (Birkvad, 2019; Leuchter, 2014; Yanasmayan, 2015) makes the active dimension of citizenship ("acts of citizenship") far less relevant in their narratives. Unlike that highlighted by theorists of active citizenship (Isin, 2008; Isin \& Saward, 2013), our participants' political and civic engagement is very week, and political rights are basically seen as the right to vote in national elections. At the same time, some Italian and Spanish migrants refusing to apply for a British passport could be interpreted as a political act. Applying for British citizenship, for instance, would mean accepting those structural constraints (hostility towards migrants and insecurity around the future due to the Brexit vote) that have pushed them to do so. A similar attitude in Germany could indicate Euroscepticism or relate to those who condemn Germany's stance towards Southern European countries during the Eurozone crisis (Graeber, 2016). In other words, not wishing to apply for citizenship and coping with such constraints may be seen as a way of either protesting or resisting a general hostility towards migrants that is increasingly widespread.

Fourth, as regards the comparison between Italians and Spaniards, no relevant results emerged. This was expected as they share many similarities: both Spain and Italy have a long history of attachment to the EU, their citizens generally identify with the European identity and also hold strong national ones (Rother \& Nebe, 2009) and their emigration patterns are quite similar (Dimitriadis et al., 2019).

Fifth, when looking at participant characteristics, it has been argued, in a few cases, that less qualified individuals, families and those planning to stay in a host country for many years have a more strategic view of citizenship. Whereas, previous mobility experience indicates greater emphasis on EU (cosmopolitan) identity. In 
addition, although gender is generally relevant when studying either mobility in general (see for instance Bonizzoni, 2018), or naturalisation in particular (Bassel et al., 2018), this was not the case in our study. As we have shown in the analytical part of our article, the gender of the respondents does not seem to influence either their position towards naturalisation or the considerations they put forward regarding the reasons that could induce them to make such a choice.

Sixth, as far as the Brexit referendum is concerned, many participants who live in Britain still displayed some confidence in their status and rights as EU citizens. Very few cases believed they should secure residence in Great Britain through naturalisation as a matter of urgency. However, statistical data shows a shift in the citizenship attitudes of Southern Europeans in the UK (Fig. 1), suggesting that the instrumental meaning of naturalisation prevails over cultural. This difference could depend on having conducted fieldwork research in London from November to December 2016, when this shift was just starting to take hold. People's attitudes and doubts around dual citizenship changed radically when the British Prime Minister confirmed that the UK intended to leave the EU at the end of 2016 and, finally, triggered Article 50 - the mechanism to set the formal procedure for the UK to withdraw from the EU in motion-on March 292017. Therefore, rather than being insecurities surrounding the effects of the Brexit vote, it seems to be the very implementation of the exit process that forced Southern Europeans to downplay the role of citizenship on their identity and decouple emotional aspects. Rather than reacting only preventively to cope with uncertainties around their legal status and fears about the future (Alarian, 2017; Graeber, 2016), it can be argued that patterns in naturalisations do change when migrants are to definitely forfeit EU citizenship rights. This may make the pay-off of citizenship higher also for migrants coming from Western prosperous countries (Vink et al., 2013).

Since the empirical material used in this article is part of a project predominantly focused on intra-EU mobile people with quite short migration trajectories, we could not compare those considering applying for naturalisation to those that have already been naturalised. In addition, a comparison with a different migrant group in terms of cultural traits (e.g. people from Baltic countries) may have provided us with a deeper understanding of attitudes towards citizenship acquisition.

Finally, the results of our study may have some relevance for EU policy makers. We show that European citizenship is still mainly perceived as access to rights while the idea of a "Citizens' Europe" with its emphasis on cultural belonging and solidarity seems scarcely present and relevant in the accounts of our participants. Even previous mobility experiences do not seem to be sufficient to create a sense of belonging to the European Union, thus questioning the effectiveness of student exchange programmes between EU countries.

Acknowledgements We would like to thank Maricia Fischer-Souan for her contribution to analyse the empirical material and for her useful suggestions and comments on the results presented in the comparative reports in the frame of the GEMM project on Work Package 4.

Funding Open access funding provided by Università degli Studi di Milano within the CRUI-CARE Agreement. The authors gratefully acknowledge the funding received for this project from the European Union's Horizon 2020 programme under grant agreement 649255-GEMM. 
Open Access This article is licensed under a Creative Commons Attribution 4.0 International License, which permits use, sharing, adaptation, distribution and reproduction in any medium or format, as long as you give appropriate credit to the original author(s) and the source, provide a link to the Creative Commons licence, and indicate if changes were made. The images or other third party material in this article are included in the article's Creative Commons licence, unless indicated otherwise in a credit line to the material. If material is not included in the article's Creative Commons licence and your intended use is not permitted by statutory regulation or exceeds the permitted use, you will need to obtain permission directly from the copyright holder. To view a copy of this licence, visit http://creativecommons.org/licenses/by/4.0/.

\section{References}

Alarian, H. M. (2017). Citizenship in hard times: Intra-EU naturalisation and the Euro crisis. Journal of Ethnic and Migration Studies, 43(13), 2149-2168.

Ambrosini, M. (2018). Irregular immigration in Southern Europe. Palgrave Macmillan.

Aptekar, S. (2016). Making sense of naturalization: What citizenship means to naturalizing immigrants in Canada and the USA. Journal of International Migration and Integration, 17(4), 1143-1161.

Bassel, L., Monforte, P., \& Khan, K. (2018). Making political citizens? Migrants' narratives of naturalization in the United Kingdom. Citizenship Studies, 22(3), 225-242.

Bauböck, R. (2010). Studying citizenship constellations. Journal of Ethnic and Migration Studies, 36(5), $847-859$.

Bellamy, R. (2008). Evaluating Union citizenship: Belonging, rights and participation within the EU. Citizenship Studies, 12(6), 597-611.

Birkvad, S. R. (2019). Immigrant meanings of citizenship: Mobility, stability, and recognition. Citizenship Studies, 23(8), 798-814.

Bloemraad, I., \& Sheares, A. (2017). Understanding membership in a world of global migration: (How) does citizenship matter? International Migration Review, 51(4), 823-867.

Bonizzoni, P. (2018). Challenging the social reproduction crisis: Italian middle-class families in London. Journal of Family Studies, 24(1), 25-40.

Coletto, D., \& Fullin, G. (2019). Before landing: how do new European emigrants prepare their departure and imagine their destinations? Social Inclusion 7(4)39-48. https://doi.org/10.17645/si.v7i4.2381

de Groot, G. R., Vink, M. P., \& Honohan, I. (2011). Loss of citizenship, EUDO citizenship, [GLOBALCIT], policy briefs. Retrieved from Cadmus, European University Institute Research Repository at http://hdl.handle.net/1814/51626

Della Puppa, F., \& King, R. (2019). The new 'twice migrants': Motivations, experiences and disillusionments of Italian-Bangladeshis relocating to London. Journal of Ethnic and Migration Studies, 45(11), 1936-1952.

Dimitriadis, I. (2018). "Asking around": Immigrants' counterstrategies to renew their residence permit in times of economic crisis in Italy. Journal of Immigrant \& Refugee Studies, 16(3), 275-292. https:// doi.org/10.1080/15562948.2016.1273433

Dimitriadis, I., Fullin, G., \& Fischer-Souan, M. (2019). Great expectations? Young Southern Europeans emigrating in times of crisis. Mondi Migranti, (3), 127-151. https://doi.org/10.3280/ MM2019-003007

Favell, A. (2008). EUROSTARS AND EUROCITIES Free movement and mobility in an integrating Europe. Wiley-Blackwell.

Finotelli, C., La Barbera, M. C., \& Echeverría, G. (2018). Beyond instrumental citizenship: The Spanish and Italian citizenship regimes in times of crisis. Journal of Ethnic and Migration Studies, 44(14), 2320-2339.

Glaser, B. G. (2005). The grounded theory perspective III: Theoretical coding. Sociology Press.

Graeber, J. (2016). Citizenship in the shadow of the Euro crisis: Explaining changing patterns in naturalisation among intra-EU migrants. Journal of Ethnic and Migration Studies, 42(10), 1670-1692.

Griffiths, D., \& Maile, S. (2014). Britons in Berlin: Imagined cityscapes, affective encounters and the cultivation of the self. In M. Benson \& N. Osbaldiston (Eds.), Understanding lifestyle migration: Theoretical approaches to migration and the quest for a better way of life (pp. 139-159). Palgrave.

Guma, T., \& Dafydd, R. J. (2019). 'Where are we going to go now?' European Union migrants' experiences of hostility, anxiety, and (non-) belonging during Brexit. Population, Space and Place, 25(1), 1-10. 
Harpaz, Y., \& Mateos, P. (2019). Strategic citizenship: Negotiating membership in the age of dual nationality. Journal of Ethnic and Migration Studies, 45(6), 843-857.

Isin, E. F. (2008). Theorizing acts of citizenship. In E. F. Isin \& G. M. Nielsen (Eds.), Acts of citizenship, (pp (pp. 15-43). Palgrave Macmillan.

Isin, E. F., \& Saward, M. (Eds.). (2013). Enacting European citizenship. Cambridge University Press.

Isin, E. F., \& Turner, B. S. (Eds.). (2002). Handbook of citizenship studies. Sage.

Joppke, C. (2010). The inevitable lightening of citizenship. European Journal of Sociology, 51(1), 9-32.

Joppke, C. (2019). The instrumental turn of citizenship. Journal of Ethnic and Migration Studies, 45(6), 858-878.

King, R., Lulle, A., Parutis, V., \& Saar, M. (2018). From peripheral region to escalator region in Europe: Young Baltic graduates in London. European Urban and Regional Studies, 25(4), 284-299.

Koikkalainen, S. (2019). Intra-European migrants and the question of integration: Citizenship in the lives of Finnish migrants in Europe. Nordic Journal of Migration Research, 9(2), 257-273.

Koopmans, R., Statham, P., Giugni, M., \& Passy, F. (2005). Contested citizenship. immigration and cultural diversity in Europe. University of Minnesota Press.

Lafleur, J.-M. \& Stanek, M. (Eds.) (2017). South-North migration of EU citizens in times of crisis. SpringerOpen

Leuchter, N. (2014). Creating other options: Negotiating the meanings of citizenships. Citizenship Studies, 18(6-7), 776-790.

Monforte, P., Bassel, L., \& Khan, K. (2018). Deserving citizenship? Exploring migrants' experiences of the 'citizenship test' process in the United Kingdom. The British Journal of Sociology, 70(1), 24-43.

Muxel, A. (2009). EU movers and politics: Towards a fully-fledged European citizenship? In R. Ettore \& A. Favell (Eds.), Pioneers of European integration: Citizenship and mobility in the EU (pp. 156178). Edward Elgar.

Portes, A., \& Bach, R. L. (1985). Latin journey. Cuban and Mexican immigrants in the United States. University of California Press.

Portes, A., \& Rumbaut, R. G. (2001). Legacies: The story of the immigrant second generation. University of California Press.

Ranta, R., \& Nancheva, N. (2019). Unsettled: Brexit and European Union nationals 'sense of belonging. Population, Space and Place, 25(1), 1-10.

Rother, N., \& Nebe, T. (2009). More mobile, more European? Free movement and EU identity. In R. Ettore \& A. Favell (Eds.), Pioneers of European integration: Citizenship and mobility in the EU (pp. 120-155). Edward Elgar.

Simola, A. (2018). Lost in administration: (Re)producing precarious citizenship for young universityeducated intra-EU migrants in Brussels. Work, Employment and Society, 32(3), 458-474.

Shaw, J. (2020). EU citizenship: Still a fundamental status? In R. Bauböck (Ed.), Debating European citizenship (pp. 1-20). Springer.

Soysal, Y. N. (1994). The limits of citizenship: Migrants and postnational membership in Europe. University of Chicago Press.

Strumia, F. (2017). Supranational citizenship. In A. Schachar, R. Bauböck, I. Bloemraad, \& M. Vink (Eds.), The Oxford handbook of citizenship (pp. 669-694). Oxford University Press. ch. 30.

Vink, M. P., Prokic-Breuer, T., \& Dronkers, J. (2013). Immigrant naturalization in the context of institutional diversity: Policy matters, but to whom? International Migration, 51(5), 1-20.

Yanasmayan, Z. (2015). Citizenship on paper or at heart? A closer look into the dual citizenship debate in Europe. Citizenship Studies, 19(6-7), 785-801. https://doi.org/10.1080/13621025.2015.1053793

Yang, P. Q. (1994). Explaining immigrant naturalization. International Migration Review, 28(3), 449-477.

Publisher's Note Springer Nature remains neutral with regard to jurisdictional claims in published maps and institutional affiliations. 